\title{
AANBIEDING VAN KERKGESKIEDENIS OP KATKISASIE
}

\section{Probleemstelling}

Die kategese openbaar dikwels dat die kind 'n leerprobleem t.o.v. sekere stof het en dat die kategeet aangegryp word deur 'n gevoel van onvermoë en frustrasie. Dit is in ons tyd miskien veral die geval met die Kerkgeskiedenis in katkisasie. Moontlik is daar selfs Gereformeerde katkisasies waarin Kerkgeskiedenis selfs nie aangebied word nie. In ander gevalle word liefs net "vertel" en liewer niks terug getoets nie - met die hoop dat daar iets sal "vas steek".

Jy raak egter oortuig dat die kerkgeskiedenis op katkisasie nie die verbondskind vorm om homself met die strydende kerk te identifiseer en sy roeping in die gebeure van sy eie tyd verantwoordelik te begryp nie.

\section{Enkele redes vir die probleem}

Eerstens moet die weerstand teen die verlede en die devaluasie van geskiedenis as sodanig genoem word. Hierdie anti-geskiedenis en anti-tradisie-houding vorm die eensydige teenpool vir net so 'n eensydige tradisionalisme wat weer net met die gesig na die verlede leef. Hierdie anti-hcuding kom baie sterk onder gereformeerdes, in die na-oorlogse Nederland maar ook onder ons in Suid-Afrika voor.

Enkele oorsake vir hierdie houding kan genoem word. 'n Mens moet ' $n$ oog hê vir die feitlik religieuse rol wat die ewolusionisme in die denke van die Westerse mens gespeel het in die eeu van natuurwetenskap en tegniese ontploffings. Die optimistiese idee van „ontwikkeling” en „moderne tyd”, skyn soos die son. Eerder as om ontwikkeling dankbaar en in sy beperkinge te deurgrond, glo die mens vandag dat die verlede die laere en agterlike en die eietydse die hoëre en betere verteenwoordig, trouens die menslike utopia en ryk van saligheid is vlak voor die deur, as ons maar net die remminge van die ,verlede" kan afskud.

Gepaard hiermee kom die eksistensialisme met sy nadruk op die moment, die eie persoonlike keuse in verantwoordelikheid van oomblik tot oomblik. Elke moment is 'n totaal nuwe geleentheid. Die band aan die verlede en die tradisie rem hierdie eksistensiële beslissings. Saam met die ewolusionisme verheerlik die eksistensialisme die „change" en het iets gemeen met die rewolusie.

Die gees van rewolusie vanuit die Marxistiese wêreld versterk hierdie inslag, omdat die rewolusie, soos die woord aandui, in sy wese anti-histories en vyandig teenoor die tradisie is.

Mens sou verder kon wys op die pragmatisme wat by die kapitalisme pas, die materialisme in die eeu van naturalisme. - Die devaluasie van die geestelike kultuurwaardes moet noodwendig ook die kerk en sy geskiedenis tref. Die geskiedenis kan immers geen loon of nut in terme van rand en sente of glans met neon-ligte lewer nie. Die angs om sy bestaan dryf die na-oorlogse wêreld in 'n ekumene - en die geskiedenis bedreig die eenwording. 
Tweedens kan mens baie kortweg ander oorsake vir die devaluasie van Kerkgeskiedenis noem: die gebrek aan gevormde historiese $\sin$ in die ouerhuis en skool, sodat talle katkisante eintlik in die Kerkgeskiedenis te doen kry met 'n groot onbekende; probleme by die kategeet in die wyse van oordrag, byvoorbeeld selfs al net deur 'n gebrekkige motivering, verkeerde metodes, swak kontak, gebrekkige voorbereiding vir die les, swak tydsindeling, ens. Weet die kategeet presies wat hy elke les wil aanbied en waarom hy dit wil doen? Gebeur dit nie maar dikwels omdat die "Sinode" dit wenslik ag nie? Probleme rondom die kategeet moet 'n leerprobleem by die katkisant na vore bring.

\section{Die doel van die kategese}

In die katkisasie word die Woord van God opvoedkundig aangewend om mense tot mondige belyders van die Gereformeerde geloof te makk. In ons katkisasies is die mense wat onderrig word, meesal die verbondsjeug - in enkele gevalle kom nou al 'n evangelisasiegeval in 'n klassie by.

Die kategese wil dus primêr die Woord van God indra in die gedagte en leef-wêreld van die kind sodat hy as 'n gelowige mens selfstandig sy roeping as Gereformeerde Christen in hierdie wêreld aanvaar. Omdat dit ook om hierdie byvoeglike naamwoord „Gereformeerde" gaan, is die Kerkgeskiedenis nodig in die katkisasieleerplan.

Sommige wil alreeds die kategese liefs sonder hierdie kwalifikasie van "Gereformeerd" sien. Die woord „gereformeerd" is immers histories verankerd. Daarin lê opgesluit 'n historiese gebeurtenis, naamlik 'n terugkeer, 'n hervorming, 'n reformasie tot die Woord van God - Dit is in die geskiedenis herhaaldelik aanwysbaar en moet in die lewe van die Christen daagliks nog plaasvind.

Die katkisant moet as gelowige individu, as lid van die kerk (gemeente) en as mens in die wye menslike samelewing tot bewuste geloofsrypheid en -mondigheid kom. Die kategese wil nie net 'n mens vorm wat in die binnekamer tot God kan bid nie of wat hier en nou eredienstig kan saamleef nie, maar wil die mens godsdienstig volwasse maak. Daarvoor wend die kategese die leerstof van die Bybel, die Belydenis en die Kerkgeskiedenis as vernaamste leermiddels (en ook in die orde van belangrikheid) aan. Die Bybel bly ook norm vir en in die aanbieding van die Kerkgeskiedenis - trouens is self ook bron vir die oudste Kerkgeskiedenis (die O.T. en die eerste N.T. kerke). Die leerinhoud is onlosmaaklik geïntegreer.

\section{Die vorme van die kategese}

Die kind ontluik te midde van 'n wye verskeidenheid van dinge wat vir hom totaal vreemd is en wat hy een vir een moet leer ken, natuurdinge (lig, geluid, bome, kos, klere, diere, plante ens.), kultuurdinge (taal, gebeure, prestasies, arbeid), mens-dinge soos die gesinslewe, omgang, ens. In sy jong jare het die kind se godsdiens ook vir hom te doen met die konkrete dinge soos diere, plante, mense, ouers, 
gebeurtenisse, ens. Die leiding wat hy van sy ouers ontvang is hier van die allergrootste belang. Ook sy kerk leer hy aanvanklik konkreet ken en nie as 'n belydenis-gemeenskap nie.

Nietemin is die insigte en begrip wat hy primêr in die huislike kategese ontvang, van die grootste belang in sy proses van ontwikkeling waarin hy van die konkrete na die meer abstrakte begrip moet beweeg. Kinders wat nie hierdie elementêre huiskatkisasie gehad het t.o.v. godsdiens in die algemeen en t.o.v. die begrip ,gereformeerd" in die besonder nie sal 'n leerprobleem openbaar in vergelyking met ander wat 'n gesonde (belangrik!) huiskatkisasie gehad het.

Op dieselfde wyse sou die sekondêre opvoeding in die skool bespreek kon word, in soverre dit die kind ryp maak om die kategese te ontvang. Die probleme word egter vir die kategeet vermenigvuldig omdat die skool of probeer om ,godsdiens" neutraal te onderrig of dikwels die indruk wek dat die periodes liefs vir „belangriker" doeleindes gebruik moet word.

Die kerk-katkisasie moet eintlik die kind ryp maak ,om te verstaan", d.w.s. om met oortuiging te kan bely. Die elementêre feitekennis moet die kind in sy huis en skool kon opdoen.

Kortom, die kategese moet die kind help om betekenis te gee aan konkrete en abstrakte werklikhede; hy moet dit kan orden, 'n plek daaraan kan toewys, verbande daartussen kan lê; opinie omtrent werklikhede (konkreet en abstrak, bv. die kerk en sy belydenis) kan vorm; hom met dinge kan identifiseer of hom van dinge (konkreet en abstrak) kan distansieer. Hy moet bv. die abstrakte begrip "sonde" in verband kan bring met die konkrete "kerk" en 'n standpunt inneem oor die „,kerk" as 'n vergadering van „,sondaars” en/of ",heiliges" in Christus. Sodra dit gebeur, het die persoon tot geestelike rypheid en mondigheid gekom. Vroeër is rypheid sy ,,jare van onderskeiding" genoem.

\section{Kerkgeskiedenis as leerstof in katkisasie}

In die skool en universiteit gaan dit om die doel om die Kerkgeskiedenis as sodanig te ken. In die katkisasie vorm die Kerkgeskiedenis net 'n middel waarmee die katkisant tot geestelike mondigheid gehelp word met die oog op sy omvattende lewenswerklikheid. Gevolglik moet in die katkisasie nie die feitekennis op sigself nie, maar die vormende waarde van Kerkgeskiedenis nagestreef word.

Die Kerkgeskiedenis is egter ook meer as net kennis van die verlede van die kerk met die oog op die hede en toekoms. Die Kerkgeskiedenis openbaar ook God se werke met mense en ten spyte van mense (Art. 2 NGB). Kerkgeskiedenis is daarom ondergeskik aan die Bybel, maar vul nietemin die oudste kerkgeskiedenis wat die Bybel vanaf Pinkster en die oudste gemeentes beskryf tot vandag toe aan. Kerkgeskiedenis vertel in 'n sekere sin die verhaal van wat God in Christus deur die Heilige Gees op aarde doen, want Hy realiseer sy koninkryk in en deur middel van sy getroue en gehoorsame kerk - en hy verbreek die werke van ongehoorsaamheid. 
Die Woord van God (veral die profesie) belig die geskiedenis en die geskiedenis belig die profesie. Die heilsgeskiedenis en die kerkgeskiedenis is vervleg en speel af tussen 'n begin en 'n eindpunt. Die katkisasie moet laat uitkom wat die Kerkgeskiedenis ons van die werke van God openbaar en elke gelowige moet weet hoe God met hom en die gebeurtenisse van sy tyd besig is om die geskiedenis van sy kerk te skryf en na 'n voleinding te voer.

Kerkgeskiedenis openbaar ook die werke van die mens as tweede oorsaak, want die mens is verantwoordelik vir sy werke waarmee hy deelneem aan die geskiedenis wat gemaak word. Die mens se deelname staan in die teken van gehoorsaam of ongehoorsaam wees aan die Woord en Gees van God. Kerkgeskiedenis moet dus in katkisasie so aangebied word dat die mens se individuele en korporatiewe verantwoordelikheid voor God na vore kom.

Dit is duidelik dat die Kerkgeskiedenis nie 'n plus by die Bybel in katkisasie vorm nie. Die kategese gebruik integrale leerstof om die katkisant juis in sy tyd en werklikheid te oriënteer. Hy moet juis uit die geskiedenis, met die Bybel as norm, sy verantwoordelikheid leer en sy stelling neem in gehoorsaamheid aan God. Selfs die kerkinstituut bly aan hierdie norm onderworpe. Die katkisant is immers geroepe om selfs met offers en opofferinge hom volledig te identifiseer met die kerk-instituut - en waar dit nie kan nie, sy roeping t.o.v. die instituut te begryp en verantwoordelik deel te neem aan die kerk-wees waar die kerk plaaslik geopenbaar word.

Vanselfsprekend is nie elke kerkhistoriese feit belangrik nie. Die feite waarin die gehoorsaamheid of die ongehoorsaamheid (die formasie, deformasie en reformasie) in die verhouding tot God aan die lig tree, moet die leerstof beheers. Dit kom immers ook in die Openbaringsgeskiedenis na vore.

\section{Te maklik word op die verlede as verlede klem gelê}

Een van die grootste probleme met die aanbieding van Kerkgeskiedenis op katkisasie ontstaan wanneer dit as verlede aangebied word. Die verlede word dan as verlede aan die kind voorgehou. Soms word dit gedoen deur middel van 'n skitterende vertelling waarin die verlede gedramatiseer word - soms geskied dit in 'n droë kronologiese verhaal van dooie en begrawe lewe. 'n Derde probeer dalk om drama en kronologie te kombineer. Die resultaat wissel van die katkisant wat lekker ,luister" tot die een wat hoop die les is verby en in nie een geval voel kategeet en katkisant tevrede nie.

Kerkgeskiedenis moet aangebied word met die oog op die waarde van die geskiedenis vir vandag - en nie met die oog op die lewe van die gelowige martelaar-slavinnetjie of die vername mens van die verlede nie. Die kategeet moet hom derhalwe voorberei. Hy moet die relevante lyne soek en trek, byvoorbeeld van die Ariane na die Jehova-getuies vandag, ensovoorts. Wanneer die lyne getrek word, leer die Kerkgeskiedenis en geen kind sal dan ongemotiveerd luister nie. Noem maar net die Jehova-getuies by 'n les en kyk hoe spits die ore. 'n Kind wil leer met die oog op sy eie konkrete lewenssituasie. Hy wil leer wat hy weet wat hy nodig het. 


\section{Die vermoë van die kind}

Kerkgeskiedenis moet aangebied word met 'n begrip vir die leervermoë en belangstellingsfeer van die kind op sy verskillende wordingsvlakke. Sodra die Kerkgeskiedenis bo die kind se vermoë aangebied word, kan hy nie leer nie en sy plig druk hom neer.

'n Kind van 9 tot 13 jaar verkeer nog in die fantaseer-stadium. In hierdie jare is hy ingestel op die konkrete, die romantiese en avontuurlike. Dit is jammer dat ons katkisasies nie figurestudie doen nie. Die Kerkgeskiedenis kan uitnemend in mooi lesse oor die martelare, Luther op Worms, in die Wartburg, Hugenote, die inkwisisie, ens. aangebied word. Werke van De Rover en Van der Mast kan met vrug hiervoor gebruik word. Hier word die historiese verhaal en verband daargelaat en op afgeronde sketse gekonsentreer.

Vanaf ongeveer 13 jaar is die kind gereed om dieper ingelei te word tot begrip van die abstrakter karakter van die kerkgeskiedenis, die stryd om die waarheid en die Skrif. Hy kan nou die belangrike feite inneem en begryp, mits dit verstaanbaar aan hom gebied word en hy dit kan tuisbring by en in sy bekende en konkrete lewenssituasie.

Die beskikbare tyd vir ' $n$ katkisasieles is ongeveer veertig minute. Die les word gedien wanneer die periode altyd liefs in twee gedeel word. Gedurende die een gedeelte kan die Belydenis of Openbaringsgeskiedenis en gedurende die volgende twintig minute die kerkgeskiedenis behandel word. Die afwisseling hou die kind se aandag en laat hom ook wyer betrokke voel. 'n Kort hersiening of aansluiting by die vorige les en 'n kort opsomming of "toepassing" van die les aan die einde kan help om die kind se belangstelling te prikkel en hom sinvol te laat voorberei.

\section{Besondere probleme vir die kategeet}

'n Mens hoef nie te soek na die probleme waarmee kategete te doen kry nie. In die eerste plek spreek dit vanself dat die katkisasieles nie ' $n$ skoolles is nie, maar tog plaas die gebrek aan tegniese hulpmiddels ' $n$ blok aan die been van die kategeet. Hy het gewoonlik geen apparaat en selfs baie min tyd om sy lesse te illustreer. Die kategeet wat oor 'n toegeruste klaskamer met landkaarte, kronologiekaarte, plate, fotos met byskrifte, ligbeelde, prente ens., beskik is gelukkig. Maar hoeveel is daar?

Soms mag die kategeet self om baie redes wat wissel vanaf gebreke in sy opleiding tot miskien gebrekkige voorbereiding vanweë te veel werk of te min belangstelling, nie in staat wees om sinvol verbande te lê tussen die les en die leefwêreld van die kinders nie. Trouens as opgeleide onderwysers Geskiedenis op skool vermoor met hulle benadering, metodes en toetsing (vgl. C. J. S. Langenhoven, Historia, Junie 1967) — wat van die kategeet?

Soms mag die kategeet vanweë gebrekkige kennis van die didaktiek nie volle waarde uit sy poging trek nie. 'n Goeie les kan byvoorbeeld verlore gaan omdat die kategeet agter 'n tafel sit 
terwyl hy dit gee; hy die kind nie medewerkend betrek by sy poging nie; hy die kinders te veel as klas en te min individueel benader of omgekeerd; hy te min rekening hou met die ouderdomme, skoolstanderd, vakinhoude aan die skole; hy te min hom inleef en indink in die presiese leef- en dinkwêreld van die kinders voor hom; hy nie genoeg rekening hou met weerstand in ouerhuise bv. teen die geskiedenis van die kerk omdat een van die ouers nominaal gereformeerd, onkerklik of iets dergeliks is nie; 'n ouerhuis sterk piëtisties of deïsties ingestel is en derhalwe die kerkgeskiedenis met antipatie bejeën, ens.

In die tweede plek lewer die ordening van die kerkgeskiedenis 'n probleem. Gewoonlik word die kerkgeskiedenis kronologies in 'n reguit lyn georden. Dit begin by Pinkster en eindig min of meer vandag. Die probleem is dat die kind nou eers aan die einde van die hele kursus 'n oorsig kry en verbande kan lê. 'n Ander metode is om die Kerkgeskiedenis feitlik eers telegramstyl op te som en as 't ware die draad te span. Daarna kan dan teruggekeer word en aspekte in besonderhede behandel word.

'n Derde metode kan wees om sekere temas te kies en dan die geskiedenis daarvan te behandel, bv. Belydenis, Skrifgesag, Kerkbesef, Sakramente, ens. Die huidige situasie van die tema kan dan eers verduidelik word en daarna kan in die geskiedenis teruggegaan word. Veral t.o.v. 'n beweging soos die Wêreldraad van Kerke, Christelike Instituut ens., sou dit 'n goeie metode wees - maar dit laat weer 'n leemte omdat die katkisant nou nie die kerk self as 'n konkrete werklikheid ontmoet nie.

Nadat die kerkgeskiedenis op een of ander manier as leerstof georden is, bly die belangrikste probleem egter nog steeds die motivering van die kategeet self. Hoe gaan hy die probleem aanpak? Indien 'n kategeet met ' $n$ les van wal steek en hy weet nie presies wat hy aan die kinders wil meedeel nie, warom hy dit wil doen nie en presies hoe hy daarmee kerklike besef, begrip van roeping en identifikasie met die gereformeerde belydenis wil bewerkstellig nie - moet hy dalk maar oorweeg om die klas af te gee. Indien hy dit wel gee mag dit 'n renons en afkeer en distansiëring by die katkisante oproep wat alles kan stukkend slaan wat ouers met liefde en sorg opgebou het.

Die Kerkgeskiedenis stel ongetwyfeld swaar eise aan die kategeet, maar o.i., tog nie swaarder as die ander leerstof nie, omdat die kerkgeskiedenis maklik by die leefwêreld aansluit. Die kategeet moet sy arbeid en vernuf aanwend en altyd aanwerk op die doel dat die katkisant die Gereformeerde standpunt sal inneem. Eie twyfel oor een of ander aspek van kontemporêre ,gereformeerd"'wees pas nie in kategese nie. Die kategese moet positief gerig wees.

Die kategeet moet derhalwe ook sy eietydse strominge goed ken en veral die negatiewe strominge wat vanuit die wêreld of vanuit afwykende kringe ' $n$ werfkrag op die jeug en katkisante het. In katkisasie moet hy positief standpunt inneem en aan die nog rypende katkisante 'n ideaal gee - en hulle nie beswaar met sy kritiek en versugtinge nie. 


\section{Bybelonderrig en Kategese}

Gereformeerdes moet dankbaar wees dat die volgehoue arbeid van opvoedkundiges soos proff. J. Chris Coetzee en H. J. J. Bingle daartoe gelei het dat in Transvaalse skole 'n redelike Godsdiensonderrig of Bybelkunde-onderwys gegee word. 'n Mens moet ook die baanbrekerswerk waardeer wat die P.U. vir C.H.O. d.m.v. die personeel van die Teologiese Skool gedoen het i.v.m. die opleiding van behoorlike leerkragte vir dié vak op skole. Dit word tans oral nagevolg.

Dit is egter jammer dat die dosente vir die Universitêre Bybelkunde eksklusief uit predikante, teoloë en oud-predikante bestaan. Die rede hiervoor moet waarskynlik gesoek word in eensydige nadruk op die inhoudelike.

Die eksklusiewe benadering bring mee dat geen deurknede opvoedkundiges aan die Bybelkunde-departement van die P.U. vir C.H.O. werk nie, terwyl by Opleidingskolleges en ander universiteite sonder teologiese skole onderwysers wel deur onderwysers opgelei word om Bybelkunde op skool te gee. Die Kategese en die aanbieding van Kerkgeskiedenis op katkisasie (soos ook alle ander leerstof) kon ontsaglik baat indien bekwame en ervare opvoedkundiges op akademiese gebied besin en publiseer oor didaktiese vraagstukke, soos o.a. die aanbieding van kerkgeskiedenis. Dit is immers gereformeerd om gebruik van die Bybel nie net vir „spesialiste" te reserveer nie.

Wanneer ons die taak van die skool en die kerk t.o.v. kategese onderskei, moet daar ook 'n gesonde wisselwerking en verband wees, sonder dat die een die ander uitskakel. Die beginsel hou in dat die opleiding vir die kategese primêr deur predikante en die opleiding vir Bybelonderwys op skole primêr deur opvoedkundiges moet geskied. Dit lyk daarom gewens dat teoloë die inhoudelike handboeke vir die Bybelkunde lewer. - Op universiteit kan teoloë die seniorklasse inhoudelik help lei. Aan die ander kant moet opvoedkundiges in Bybelkunde en die onderrig daarvan akademies spesialiseer en op hulle beurt help in die vorming van kategete. Dit sal ook verhoed dat Teologie en Bybelkunde soos 'n A en B Teologiese kursus wil lyk, sonder dat laasgenoemde die principium theologiae, nl. die Skrif in sy oorspronklike vorm as basis het. Bybelkunde is hoogstens toegepaste teologie en het as vak primêr ontstaan met 'n opvoedkundige doel al hou dit ook waarde in vir nie-onderwysers. Dit is egter wesenlik anders as die teologie wat die wetenskap as sodanig beoefen.

\section{Samevatting}

Kerkgeskiedenis vorm ' $n$ essensiële en belangrike leerinhoud van die kategese omdat die kerk as instituut nie los mag staan van die mondige gelowige as lid van die liggaam van Christus nie. Kerkgeskiedenis moet dus as ' $t$ ware die konkrete kerk (vergadering van gelowiges) aan die katkisant voorstel en hom in die tyd leer waarom 
'n mens vandag Gereformeerd moet wees en ook 'n bydrae lewer om te toon hoe 'n mens gereformeerd moet wees. Tegelyk moet die Kerkgeskiedenis die katkisant vorm om wat is te onderskei van wat was en van wat kon wees en selfs van wat moet wees.

Sodra die katkisant hierdie onderskeiding verwerf het, kan hy eventueel op die derde vraag van die formulier by die aflê van geloofsbelydenis, of die vierde vraag in die formulier vir volwasse doop of die tweede vraag by die kinderdoop positief antwoord. Die belangrikheid van Kerkgeskiedenis vir katkisasie maak dit wenslik dat kinders tussen 9 en 13 ook al op 'n wyse wat by hulle leeftyd pas, ingelei word in die Kerkgeskiedenis.

Die aanbieding van Kerkgeskiedenis kan eventueel veel baat vind indien daar in die Bybelkunde as Universiteitskursus ook deurknede opvoedkundiges betrek word om juis oor die aspekte van aanbieding resultate te lewer wat die kategese kan bevrug.

Hammanskraalse Teol. Skool.

B. Spoelstra. 